Nippon Suisan Gakkaishi $\quad \mathbf{5 3 ( 1 2 ) , 2 2 4 9 - 2 2 5 3 ( 1 9 8 7 )}$

\title{
Fatty Acid Composition of Triglycerides of Rock Crab Cancer irroratus Lipid
}

\author{
Toshio Takeuchi*1 and Robert G. Ackman*2 \\ (Accepted July 27, 1987)
}

\begin{abstract}
The triglyceride (TG) and fatty acid compositions of rock crab Cancer irroratus, lipid were investigated by using reversed-phase high performance liquid chromatography (HPLC) of TG in combination with gas liquid chromatography (GLC) of fatty acids. After crab meal neutral lipid was separated into an acetone-soluble fraction (mainly neutral lipid, SNL) and a precipitate fraction (PF), each fraction was first examined by HPLC. TG in SNL, which had a high content of polyunsaturated fatty acids such as 20:5 and 22:6, consisted of components with partition numbers $(\mathrm{PN})$ of 36 to 52 ; however no good separation among these was observed on the chromatogram.

On the other hand, TG in PF readily separated into twelve peaks of PN 44 to 56 . Weight percentages of the main peaks of PN 48, 50, and 52 were 26, 26, and $21 \%$, respectively. As a result of GLC analysis, the fraction with PN of 44 was shown to have a high content of polyenoic acids, concentrated five times higher in mole \% than that of total PF. Fractions of all PN had more than 20 mole \% of $\mathrm{C16:0}$. It is suggested that one or more molecular species type in PF might be dominated by $\mathrm{C} 16: 0$. In this experiment, two or three peaks having the same PN were resolved by using reversed-phase HPLC. In these components with the same PN, the earlyeluting peaks had a high amount of $\mathrm{C} 18: 1$ or other monoenes, while the later-eluting peaks had much more C16: 0 .
\end{abstract}

So far, the separation of triglycerides (TG) by high performance liquid chromatography (HPLC) has been studied by a number of workers. ${ }^{1-15)}$ The TG compositions and molecular species of standard samples, plant oils and animal fats have been published in several papers. ${ }^{18-21)}$ However, TG compositions of fish lipids were investigated in only a few species, for example, black cod Erilepis zonifer, ${ }^{22-24)}$ and jack mackerel Trachurus japonicus, ${ }^{25}$ by using HPLC, and carp Cyprinus carpio, salmon Oncorhynchus nerka, Oncorhynchus masou, and eel Anguilla japonicus, ${ }^{26)}$ by using gas liquid chromatography (GLC). No report has yet appeared about the TG structures of edible invertebrates such as Crustacea, Mollusca, Echinoderms etc. It is difficult to study these TG structures, since TG of fish and other marine animals are composed of a wide variety of fatty acids including long chain and polyunsaturated fatty acids.

In this study of rock crab lipids, a precipitate fraction (PF) was obtained unexpectedly when using the acetone extraction method to recover neutral lipids. The main lipid class of this fraction was TG with a fatty acid composition rich in saturated and monoenoic acids.* This result suggested that TG of crab PF could be separated by HPLC. We report herein the TG composition of rock crab lipid by using HPLC in combination with GLC.

\section{Materials and Methods}

The neutral lipid of meal produced from rock crab Cancer irroratus caught off Nova Scotia, Canada, was recovered by the acetone separation method. ${ }^{27}$ ) The acetone solution of rock crab neutral lipid was allowed to stand for 2-3 days in a $-15^{\circ} \mathrm{C}$ freezer. The crystalline $\mathrm{PF}$ which precipitated was recovered. The low temperature acetone-soluble fraction (mainly neutral lipids, SNL) was also recovered. TG from both SNL and $P F$ fractions were further purified by preparative thin-layer chromatography (TLC). The solvent system of hexane: diethyl ether: glacial acetic acid $(80: 20: 1, \mathrm{v} / \mathrm{v})$ was used for developing the plates. ${ }^{28)}$

*1 Laboratory of Fish Nutrition, Tokyo University of Fisheries, Konan, Minato, Tokyo 108, Japan (竹内俊郎: 東京水産大学水族栄坟学).

*2 Canadian Institute of Fisheries Technology, Technical University of Nova Scotia, P. O. Box 1000, Halifax, Nova Scotia B3J 2X4, Canada (ノバスコシアエ菜大学カナダ水産研究所).

* T. Takeuchi and R. G. Ackman: unpublished data. 
HPLC was carried out with a Waters Associates $6000 \mathrm{~A}$ Chromatograph with a stainless-steel $\mathrm{C} 18 \mu$ Bondapak column $(30 \mathrm{~cm} \times 3.9 \mathrm{~mm} \quad$ I.D. $) \quad A$ Waters R-401 differential refractometer was used as the detector. Samples were injected as an acetonitrile/methyl ethyl ketone solution by means of a $\mathrm{U} 6 \mathrm{~K}$ septumless loop injector and were run using a mixture of acetonitrile-methyl ethyl ketone $(2: 1, \mathrm{v} / \mathrm{v})$ as the mobile phase at $25^{\circ} \mathrm{C}$ (room temperature). A flow-rate of $2.0 \mathrm{~m} / / \mathrm{min}$. was used. Each fraction obtained from the TG from PF was collected and each re-injected individually into the HPLC in order to obtain a higher purity. Then each purified fraction was transesterified and analysed for fatty acid composition by GLC.

The fatty acid compositions of TG fractions were determined as methyl esters, prepared by the method of Metcalfe et al., ${ }^{28)}$ using a Perkin-Elmer (Sigma-3B) gas chromatograph and a flexible fused-silica capillary column coated with SUPELCOWAX-10 (bonded Carbowax-20M), $30 \mathrm{~m} \times 0.25$ $\mathrm{mm}$ I.D. Operating conditions were described in a previous paper. ${ }^{30)}$

\section{Results and Discussion}

The principal fatty acid components of TG from both SNL and PF of rock crab meal lipid are shown in Table 1. The fatty acid compositions of TG in SNL showed high contents of polyunsaturated fatty acids (PUFA) such as eicosapentaenoic acid (20:5) and docosahexaenoic acid (22:6). Similar results have been observed in some other crabs such as dungeness crab Cancer magister, ${ }^{31}$ queen snow crab Chionoecetes opilio, ${ }^{322}$ red crab Pleuroncodes planipes, ${ }^{33)}$ horseshoe crab Xiphosura (Limulus) polyphemus, ${ }^{34)}$ chinese crab Eriocheir sinensis, ${ }^{35)}$ crabs Carcinus maenas, ${ }^{36)}$ and Cyclograpsus punctatus. ${ }^{37)}$ It has also been shown that the phospholipids of acetone-insoluble fraction also have high amounts of these fatty acids.* On the other hand, TG of PF was rich in saturated and monoenoic acids, for example C16:0, C20:1 and $\mathrm{C} 22: 1$. It is well known that some marine oils and fish oils have high amounts of $\mathrm{C} 20: 1$ and of $\mathrm{C} 22: 1{ }^{38,30)}$ In addition, rock crab lipids also had high proportions of $\mathrm{n} 7$ monoenoic fatty acid isomers, for example $8.4 \%$ of $16: \ln 7,5.9 \%$ of $18: 1 \mathrm{n} 7$ and $3.4 \%$ of $20: \ln 7$ in TG of SNL, $4.9 \%$ of $16: 1 \mathrm{n} 7,5.8 \%$ of $18: \ln 7$ and $2.5 \%$ of $20: 1 \mathrm{n} 7$ in TG of PF. This aspect was similar to that observed in queen snow crab. ${ }^{32)}$ Total mole $\%$
Table 1. Principal fatty acid components (Wt. \%) and (Mole \%) of triglycerides in SNL and PF from rock crab lipid

\begin{tabular}{|c|c|c|c|c|}
\hline \multirow{2}{*}{ Fatty acid } & \multicolumn{2}{|c|}{ SNL } & \multicolumn{2}{|c|}{ PF } \\
\hline & Wt. \% & Mole $\%$ & Wt. $\%$ & Mole $\%$ \\
\hline $12: 0$ & $\operatorname{tr}$ & $\operatorname{tr}$ & 0.4 & 0.6 \\
\hline $14: 0$ & 2.2 & 2.8 & 8.6 & 10.6 \\
\hline $15: 0$ & 0.7 & 0.8 & 1.6 & 1.9 \\
\hline $16: 0$ & 7.7 & 8.6 & 25.9 & 28.5 \\
\hline $18: 0$ & 1.6 & 1.7 & 4.1 & 4.0 \\
\hline$\Sigma$ Saturates & 12.2 & 13.9 & 40.6 & 45.6 \\
\hline $16: 1$ & 7.6 & 8.8 & 3.1 & 3.4 \\
\hline $18: 1$ & 15.3 & 16.0 & 10.5 & 10.5 \\
\hline $20: 1$ & 11.8 & 11.3 & 16.2 & 14.9 \\
\hline $22: 1$ & 9.7 & 8.6 & 21.9 & 18.5 \\
\hline $24: 1$ & 0.9 & 0.5 & 1.9 & 1.5 \\
\hline$\Sigma$ Monoenes & 45.3 & 45.2 & 53.6 & 48.8 \\
\hline $18: 2$ & 1.8 & 1.9 & 0.5 & 0.5 \\
\hline $20: 2$ & 1.2 & 1.2 & 0.7 & 0.7 \\
\hline $18: 3$ & 1.4 & 1.5 & 0.7 & 0.8 \\
\hline $20: 3$ & 1.1 & 1.0 & 0.4 & 0.4 \\
\hline $20: 4$ & 3.3 & 3.2 & 0.3 & 0.3 \\
\hline $20: 5$ & 9.0 & 8.9 & 0.4 & 0.4 \\
\hline $22: 5$ & 2.7 & 2.4 & 0.3 & 0.2 \\
\hline $22: 6$ & 11.1 & 10.1 & 0.7 & 0.6 \\
\hline$\Sigma$ Polyenes & 31.6 & 30.2 & 4.0 & 3.9 \\
\hline $\begin{array}{l}\text { Calculated } \\
\text { iodine value }\end{array}$ & \multicolumn{2}{|c|}{173} & \multicolumn{2}{|c|}{54} \\
\hline $\begin{array}{l}\text { Av. molecular } \\
\text { weight }\end{array}$ & \multicolumn{2}{|c|}{311} & \multicolumn{2}{|c|}{298} \\
\hline
\end{tabular}

of polyenoic acids in TG of PF was only $3.9 \%$, and the calculated iodine value (I.V.) was 54 , which was one third of that of TG of SNL (Table 1). Wada et al. demonstrated that black cod lipid containing large quantities of monoenoic acids such as C18: 1, C20: 1 and C22: 1 was considered to be a material suitable for the study of TG structure using HPLC. ${ }^{22)}$ This result suggested that TG of rock crab PF also could be separated by using HPLC.

HPLC chromatograms of TG from both SNL and $\mathrm{PF}$ are shown in Fig. 1. TG of SNL which had a high content of PUFA such as 20:5 and 22: 6 , consisted of components with partition numbers (PN) of 36 to 52, however no good separation was observed on the chromatogram from use of HPLC. Similar chromatograms of fish lipids were also reported by Wada and his coworkers. ${ }^{25,40,41)}$ On the other hand, TG of PF could be separated into twelve peaks (fr. numbers 1-12, Fig. 1, below). Some peaks (fr. numbers 1,

* T. Takeuchi and R. G. Ackman: unpublished data. 


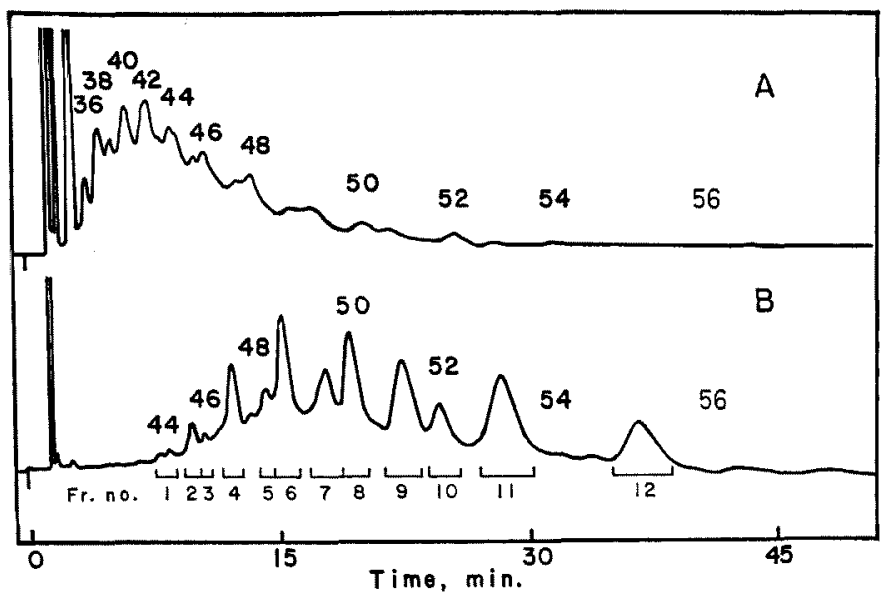

Fig. 1. HPLC chromatogram of triglycerides in the acetone-soluble fraction (A) and an insoluble precipitate fraction (B) from rock crab Cancer irroratus neutral lipid.

Table 2. Percentages of each triglyceride fraction separated by HPLC

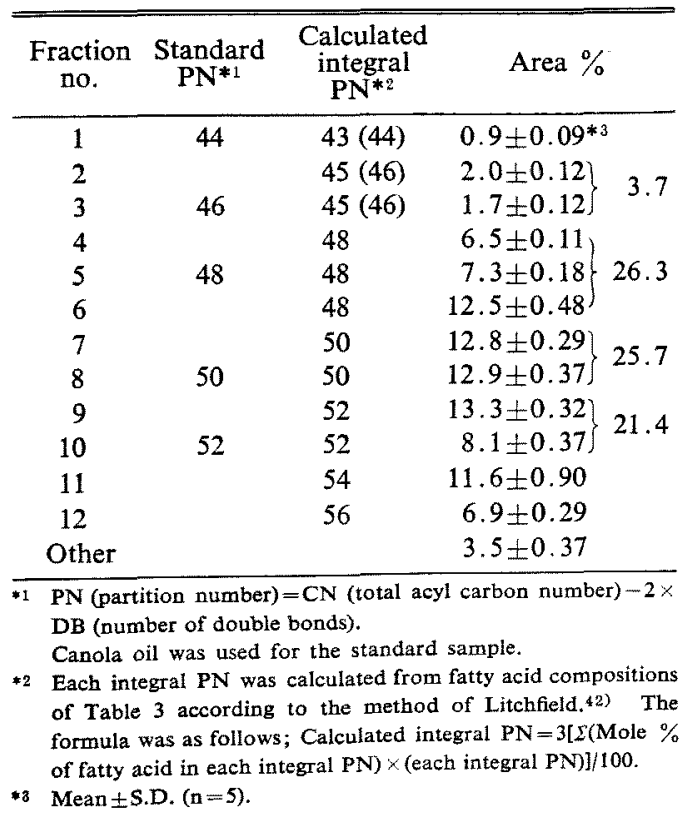

$3,5,8$, and 10) were identified by PN through retention times of standard samples (canola oil). However, the retention times of other peaks (fr. numbers $2,4,6,7,9,11$, and 12) showed values intermediate to those of standard PN.

The percentage of each fraction was calculated from its peak area in the chromatogram and is shown in Table 2 . In addition, the integral PN of each fraction was calculated from the fatty acid compositions (Table 3 ) according to the method of Litchfield. ${ }^{42)}$ As a result, PN of fraction numbers $2,4,6,7,9,11$, and 12 were confirmed as $45,48,48,50,52,54$, and 56 respectively. Odd numbers were obtained in fraction numbers 1,2 , and 3 which were however minor components. These peaks could have a little contamination with branched-chain fatty acids as well as oddnumbered fatty acids. The main TG components of rock crab PF were $26 \%$ of PN $48,26 \%$ of PN $50,21 \%$ of PN $52,12 \%$ of PN 54 , and $7 \%$ of PN 56. This result indicates that the $\mathrm{TG}$ structures of rock crab PF are very different from those of plant oils. ${ }^{1,2,8)}$

The main fatty acid composition of each fraction number peak from crab PF is shown in Table 3. Fraction 1, with a PN of 43(44), had the highest quantities of polyenoic acid which is concentrated five times higher than that of TG from PF. It is suggested that these PUFA might be concentrated under the PN of 44 because the chromatogram of TG of SNL rich in $20: 5$ and 22: 6 showed a high proportion of peaks with $P N$ of 38 to 44 (Fig. 1, above). Since fraction 3 with PN of 45 (46) has a high content of C18:2, a TG combination similar to (C16:0, C18:1, C18:2) which was reported in soybean oil ${ }^{2,21}$ and jack mackerel oil's is suggested in TG of rock crab lipid. The fatty acid compositions of the peaks with PN of 52, 54, and 56 showed simple combinations which had $\mathrm{C} 20: 1$ or $\mathrm{C} 22: 1$ as principal fatty acids, compared with those of the peaks with PN of 44 to 48 . We would also suggest that major constituent TG with $\mathrm{PN}$ of 52,54 and 56 are basically (C16: 0, C16: 0, C22: 1), (C16:0, C20: 1 , $\mathrm{C} 22: 1)$ and $(\mathrm{C} 16: 0, \mathrm{C} 22: 1, \mathrm{C} 22: 1)$ respectively. These components can be seen in jack mackerel 
Table 3. Main fatty acid compositions (Mole $\%$ ) of each fraction number of triglycerides from PF

\begin{tabular}{|c|c|c|c|c|c|c|c|c|c|c|c|c|}
\hline \multirow{2}{*}{ Fatty acid } & \multicolumn{12}{|c|}{ Fraction number } \\
\hline & 1 & 2 & 3 & 4 & 5 & 6 & 7 & 8 & 9 & 10 & 11 & 12 \\
\hline $12: 0$ & 2.4 & 1.3 & 0.9 & - & - & - & - & - & - & - & - & - \\
\hline $14: 0$ & 25.1 & 21.2 & 24.4 & 8.1 & 5.3 & 11.7 & 6.2 & 11.2 & 7.4 & 2.5 & 6.6 & 1.5 \\
\hline $16: 0$ & 20.6 & 26.5 & 26.6 & 34.6 & 25.4 & 40.8 & 24.8 & 37.5 & 20.1 & 40.1 & 21.1 & 26.0 \\
\hline $18: 0$ & 1.6 & 1.1 & 3.0 & 2.6 & 2.4 & 3.7 & 3.5 & 6.3 & 3.3 & 9.5 & 2.7 & 3.2 \\
\hline$\Sigma$ Saturates & 49.7 & 50.1 & 54.9 & 45.3 & 33.1 & 56.2 & 34.5 & 55.0 & 30.8 & 52.1 & 30.4 & 30.7 \\
\hline $16: 1$ & 8.6 & 14.6 & 6.7 & 9.6 & 5.7 & 2.8 & 4.1 & 1.6 & 0.9 & 0.5 & - & - \\
\hline $18: 1$ & 10.7 & 13.1 & 15.3 & 23.3 & 28.6 & 18.6 & 20.1 & 7.9 & 12.4 & 3.6 & 2.6 & 0.8 \\
\hline $20: 1$ & 3.6 & 3.7 & 3.1 & 7.6 & 14.0 & 12.3 & 22.6 & 16.6 & 28.0 & 12.0 & 25.2 & 5.6 \\
\hline $22: 1$ & 2.1 & 2.0 & 1.6 & 3.2 & 4.8 & 5.2 & 11.0 & 14.8 & 21.6 & 25.3 & 39.2 & 59.3 \\
\hline $24: 1$ & 0.5 & - & 0.3 & - & - & - & 0.7 & 0.8 & 0.5 & 0.3 & 0.4 & 3.1 \\
\hline$\Sigma$ Monoenes & 25.5 & 33.4 & 27.0 & 43.7 & 53.1 & 38.9 & 58.5 & 41.7 & 63.4 & 41.7 & 67.4 & 68.8 \\
\hline $18: 2$ & 1.7 & 3.6 & 7.2 & 3.0 & 1.5 & 0.2 & 0.8 & - & 0.1 & 0.2 & - & - \\
\hline $18: 3$ & 1.7 & 1.6 & 1.6 & 0.7 & 1.1 & 0.7 & 1.4 & 0.8 & 0.6 & 0.9 & - & - \\
\hline $20: 4$ & 2.0 & 1.7 & 0.9 & 0.6 & 0.6 & 0.1 & - & - & - & $一$ & - & - \\
\hline $20: 5$ & 6.0 & 2.0 & 1.1 & 0.9 & 0.4 & - & - & - & 一 & - & - & - \\
\hline $22: 6$ & 6.0 & 1.6 & 1.3 & 0.8 & - & - & - & - & - & - & - & - \\
\hline$\Sigma$ Polyenes & 17.4 & 10.5 & 12.1 & 6.0 & 3.6 & 1.0 & 2.2 & 0.8 & 0.7 & 1.1 & - & - \\
\hline \multirow{2}{*}{$\begin{array}{l}\text { Calculated } \\
\text { iodine value } \\
\text { Av. molecular } \\
\text { weight }\end{array}$} & 115 & 76 & 63 & 59 & 68 & 41 & 57 & 38 & 58 & 40 & 54 & 54 \\
\hline & 281 & 277 & 276 & 285 & 290 & 285 & 297 & 293 & 307 & 303 & 319 & 327 \\
\hline $\begin{array}{l}\text { Calculated } \\
\text { integral PN }\end{array}$ & 43 & 45 & 45 & 48 & 48 & 48 & 50 & 50 & 52 & 52 & 54 & 56 \\
\hline
\end{tabular}

oil, ${ }^{25)}$ however, they were not detected or were found only in traces in black cod lipid. ${ }^{24}$ It is suggested that the TG structures may differ from species to species. In addition, the TG combinations might be different due to seasonal variation, environmental temperature, ${ }^{43)}$ environmental condition, ${ }^{40}$ diet, etc. Each of the fractions has more than 20 mole $\%$ of $\mathrm{C16:0}$, and it is also suggested that particular molecular species (PN 4, 6,8 , and 10) of TG in PF might be dominated by C16:0. The role of $14: 0$ and of $18: 0$ is unclear.

In this connection, two or three peaks having the same PN were separated by using reversedphase HPLC. In retention times of the same PN, the early-eluting peaks have a high content of C18:1 or other monoenoic acids, on the other hand, the later-eluting peaks have more $\mathrm{C} 16: 0$ and a low content of monoenes. These phenomena were shown in fractions with $\mathrm{PN}$ of 48,50 , and 52 .

There are some reports of the separation by reversed-phase HPLC of TG species and structures in plant oils differing by double bonds or methylene groups. $\left.{ }^{8}, 18,17,18\right)$ However no publication has reported the separation of the species or struc- tures from marine oils with direct injection in reversed-phase HPLC. Our results suggest that the difference of number of double bonds in rock crab TG which might be separated by HPLC could be further improved with the development of more efficient HPLC columns and extended to more highly unsaturated TG.

\section{Acknowledgments}

The authors wish to thank Dr. J. D. Castell of the Department of Fisheries and Oceans Canada, Halifax, for the preparation of rock crab lipid and for his helpful advice on this study. This work was supported in part by an operating grant from the Natural Sciences Research and Engineering Council of Canada to R. G. Ackman.

\section{References}

1) R. D. Plattner, G. F. Spencer, and R. Kleiman: J. Am. Oil Chem. Soc., 54, 511-515 (1977).

2) S. Wada, C. Koizumi, and J. Nonaka: Yukagaku, 26, 95-99 (1977).

3) S. Wada, C. Koizumi, A. Takiguchi, and J. Nonaka: Yukagaku, 27, 579-584 (1978). 
4) B. Herslof, O. Podlaha, and B. Toregard: $J$. Am. Oil Chem. Soc., 56, 864-866 (1979).

5) M.S. F. Lie Ken Jie: J. Chromatogr., 192, 457462 (1980).

6) A. H. El-Hamdy and E. G. Perkins: J. Am. Oil Chem. Soc., 58, 49-53 (1981).

7) R. D. Plattner: J. Am, Oil Chem. Soc., 58, 638642 (1981).

8) E. Geeraert and D. De Schepper: HRC \& CC., 6, 123-132 (1983).

9) F. C. Phillips, W. L. Erdahl, J. D. Nadenicek, L. J. Nutter, J. A. Schmit, and O.S. Privett: Lipids, 19, 142-150 (1984).

10) J. J. Myher, A. Kuksis, L. Marai, and F. Manganaro: $J$. Chromatogr., 283, 289-301 (1984).

11) M. Tsimidou and R. Macrae: J. Chromatogr., 285, 178-181 (1984).

12) J. Kruger, H. Rabe, G. Reichmann, and B. Rustow: J. Chromatogr., 307, 387-392 (1984).

13) J.A. Singleton and H. W. Pattee: J. Am. Oil Chem. Soc., 61, 761-766 (1984).

14) B. Herslof and G. Kindmark: Lipids, 20, 783790 (1985).

15) K. Takahashi, T. Hirano, M. Egi, and K. Zama: J. Am. Oil Chem. Soc., 62, 1489-1492 (1985).

16) A. H. El-Hamdy and E. G. Perkins: J. Am. Oil Chem. Soc., 58, 867-872 (1981).

17) B. Petersson, O. Podlaha, and B. Toregard: $J$. Am. Oil Chem. Soc., 58, 1005-1009 (1981).

18) M. W. Dong and J. L. Dicesare: J. Am. Oil Chem. Soc., 60, 788-791 (1983).

19) F. C. Phillips, W. L. Erdahl, J. A. Schmit, and O. S. Privett: Lipids, 19, 880-887 (1984).

20) H. E. Nordby: J. Am. Oil Chem. Soc., 61, 10291031 (1984).

21) S. Wada, H. T. Truong, and C. Koizumi: Yukagaku, 34, 433-440 (1985).

22) S. Wada, C. Koizumi, A. Takiguchi, and J. Nonaka: Nippon Suisan Gakkaishi, 44, 1167 (1978).

23) S. Wada, C. Koizumi, A. Takiguchi, and J. Nonaka: Nippon Suisan Gakkaishi, 45, 611-614 (1979).
24) S. Wada, C. Koizumi, A. Takiguchi, and J. Nonaka: Nippon Suisan Gakkaishi, 45, 615-622 (1979).

25) S. Wada, C. Koizumi, A. Takiguchi, and J. Nonaka: J. Tokyo Univ. Fish., No. 67, 35-43 (1980).

26) M. Matsui, T. Watanabe, and T. Kawabata: Nippon Suisan Gakkaishi, 42, 233-237 (1976).

27) W. R. Bloor: J. Biol. Chem., 82, 273-286 (1929).

28) C. A. Eaton, R. G. Ackman, C. S. Tocher, and K. D. Spencer: J. Fish. Res. Bd. Can., 32, 507513 (1975).

29) L. D. Metcalfe, A. A. Schmitz, and J. R. Pelka: Analyt. Chem., 38, 514-515 (1966).

30) R. G. Ackman and T. Takeuchi: Lipids, 21, 117120 (1986).

31) W. V. Allen: J. Fish. Res. Bd. Can., 28, 11911195 (1971).

32) R. F. Addison, R. G. Ackman, and J. Hingley: J. Fish. Res. Bd. Can., 29, 407-411 (1971).

33) J. Van Der Veer, B. Medwadowski, and H. S. Olcott: Lipids, 6, 481-485 (1971).

34) D. J. Van Der Horst, R. C. H. M. Oudejans, A. G. Plug, and I. Van Der Sluis: Marine Biol., 20, 291-296 (1973).

35) S. Chapelle: Arch. Internat. Physiol. Biochim., 86, 398-401 (1978).

36) A. J. De Koning: J. Sci. Fd. Agric., 21, 290-293 (1970).

37) S. Chapelle: J. Exp. Zool, 204, 337-346 (1978).

38) R. G. Ackman and C. A. Eaton: Fett, Seifen, Anstrichmittle, 80, 21-37 (1978).

39) T. Takeuchi and T. Watanabe: Nippon Suisan Gakkaishi, 44, 733-738 (1978).

40) T. Ohshima, H. D. Widjaja, S. Wada, and C. Koizumi: Nippon Suisan Gakkaishi, 48, 17951801 (1982).

41) T. Ohshima, S. Wada, and C. Koizumi: Nippon Suisan Gakkaishi, 49, 1405-1409 (1983).

42) C. Litchfield: In "Analysis of Triglycerides", Academic press, New York, 1972, pp. 68-103.

43) C. Leger, P. Bergot, P. Luquet, J. Flanzy, and J. Meurot: Lipids, 12, 538-543 (1977). 